\title{
Bildediagnostikk ved nakke- og ryggsmerter
}

\author{
Sammendrag \\ Bakgrunn. Ved nakke- og ryggsmerter \\ kan bildediagnostikk avklare om det \\ foreligger alvorlige patologiske forhold, \\ men ofte har funnene usikker klinisk \\ betydning. Her gis en oppdatert over- \\ sikt over indikasjonene for slik bilde- \\ diagnostikk og betydningen av de van- \\ ligste funn.
}

\begin{abstract}
Materiale og metode. Artikkelen er bygd på kunnskapsbaserte norske retningslinjer vedrørende korsryggssmerter, utvalgte andre utgivelser og et ikke-systematisk søk i PubMed etter systematiske oversikter og randomiserte studier om bildediagnostikk ved smerter i nakke eller rygg.
\end{abstract}

Resultater. Rutinemessig bildediagnostikk ved nakke- og ryggsmerter bedrer ikke behandlingsresultatet, derfor fraråder vi dette. Bildediagnostikk er indisert der det er begrunnet klinisk mistanke om alvorlig sykdom og bør også vurderes ved manglende bedring 4-6 uker etter symptomdebut. MR-undersøkelse har høyest sensitivitet for de fleste viktige sykdommer i nakke og rygg. Degenerative forandringer i skjelett og mellomvirvelskiver, inkludert skiveprolapser, er vanlige funn også hos symptomfrie og har ofte usikker sammenheng med smerter. Degenerative beinmargsforandringer på MR (Modic-forandringer) er hyppigere hos pasienter med ryggsmerter, men har fortsatt ingen sikker betydning for valg av behandling.

Fortolkning. Ved nakke- og ryggsmerter anbefaler vi bildediagnostikk - oftest MR - kun ved mulig alvorlig tilstand eller der det er uttalte symptomer uten bedring innen 4-6 uker. Degenerative forandringer kan sjelden forklare plagene eller bidra i valg av behandling.

\section{Kjell Arne Kvistad}

kjell.arne.kvistad@stolav.no

Klinikk for bildediagnostikk

St. Olavs hospital

og

Institutt for sirkulasjon og bildediagnostikk

Norges teknisk-naturvitenskapelige universitet

\section{Ansgar Espeland}

Radiologisk avdeling

Haukeland universitetssykehus

og

Seksjon for radiologi

Institutt for kirurgiske fag

Universitetet i Bergen

Når pasienten har smerter i nakke eller rygg, er bildediagnostikk viktig for å verifisere eller avkrefte at tilstanden krever kirurgisk eller annen spesifikk behandling. Moderne bildediagnostikk gir en detaljert fremstilling av skjelett, bløtdeler og nervestrukturer og har høy sensitivitet for viktige tilstander som fraktur, tumor, inflammasjon og infeksjon $(1,2)$. Ofte viser nakke- og ryggbildene degenerative forandringer i skjelett og mellomvirvelskiver av usikker klinisk betydning (1). Klinikere som kjenner radiologienes muligheter og begrensninger, vil bedre kunne tolke bildefunnene og gi korrekt informasjon til pasienten. Det er viktig å unngå overdrevne forventninger til bildediagnostikk og unødig bekymring på grunn av bildefunn. Vi vil her gi en oversikt over indikasjonene for bildediagnostikk ved nakke- og ryggsmerter samt betydningen av de vanligste funn.

\section{Materiale og metode}

Artikkelen bygger på kunnskapsbaserte norske retningslinjer vedrørende korsryggssmerter (1) samt et ikke-systematisk søk i PubMed etter systematiske oversikter og randomiserte studier om bildediagnostikk ved korsryggssmerter som er kommet til etter avsluttet søk vedrørende bildediagnostikk ut fra disse retningslinjene (desember 2005). Tilsvarende PubMed-søk uten tidsbegrensning ble utført for bildediagnostikk ved nakkelidelser. Artikkelen er videre basert på utvalgte andre artikler og retningslinjer samt våre egne erfaringer som radiologer og forskere.

\section{Indikasjoner og henvising}

Rutinemessig bildediagnostikk ved nakkeog ryggsmerter er ikke indisert $(1,3-6)$. Randomiserte studier har vist at effekten av slik diagnostikk er liten og dels negativ når det gjelder behandlingsvalg og tilfriskning både ved uspesifikke ryggsmerter og ved ryggsmerter med nerverotsaffeksjon $(1,4)$. Heller ikke ved nakkesmerter har rutinemessig bildediagnostikk en dokumentert positiv effekt.

Bildediagnostikk er indisert når alvorlig eller spesifikk underliggende tilstand mistenkes klinisk ut fra såkalte røde flagg (1, 3-5). Slike varselsfaktorer er omtalt grundig $i$ to andre artikler i denne serien $(7,8)$. Der det er mistanke om nevrologisk eller nevrokirurgisk akuttilfelle, må ikke henvisning til bildediagnostikk forsinke den kliniske vurderingen.

Uspesifikke akutte nakke- og ryggsmerter avtar som oftest i løpet av 4-6 uker. Manglende bedring etter denne tid er i seg selv ingen sterk indikasjon for bildediagnostikk, men på dette tidspunktet bør radiologisk utredning vurderes ut fra symptomenes intensitet og karakter $(1,3,5)$. Ved nerverotsaffeksjon uten røde flagg anbefaler retningslinjene bildediagnostikk når det ikke er bedring etter 4-6 uker, og særlig hvis det er aktuelt med kirurgisk behandling $(1,5)$.

Det er viktig at henvisningen inneholder gode kliniske opplysninger. Både CT- og MR-undersøkelser skreddersys etter disse. Alvorlig sykdom kan overses hvis man velger uriktige bildesekvenser. Derfor må ikke bildediagnostikk erstatte en grundig klinisk vurdering, og klinikeren må angi hvilken problemstilling som skal avklares slik at aktuelle bildefunn kan påvises og tolkes korrekt (1). Det kan være hensiktsmessig å la radiologen avgjøre hvilken bildemodalitet som er best egnet ut fra problemstillingen. Henviste pasienter bør informeres om hovedhensikten med bildeundersøkelsen - som

\section{Hovedbudskap}

- Rutinemessig bildediagnostikk ved nakke- og ryggsmerter bedrer ikke behandlingsresultatet

- Degenerative forandringer er vanlig og har ofte usikker sammenheng med smerter

- Det er viktig å unngå overdrevne forventninger til bildediagnostikk og unødig bekymring på grunn av bildefunn 
som regel er å utelukke alvorlige tilstander eller tilstander som krever spesifikk behandling. Man bør ikke inngi forventninger om at bildene vil vise en sikker smertekilde.

\section{Bildemetoder \\ i rygg- og nakkediagnostikk}

Magnettomografi (MR) er den beste metoden for å vise degenerative forandringer og skiveprolapser i columna. Den gir god fremstilling av ryggmarg, nerverøtter og beinmarg. MR er oftest førstevalget når bildediagnostikk er indisert. Metoden har høyest sensitivitet for de fleste alvorlige tilstander (2), men er mindre egnet for detaljert fremstilling av skjelettstrukturer.

Computertomografi (CT) gir meget god fremstilling av skjelettstrukturer og er derfor førstevalget ved kartlegging av skjelettskader i forbindelse med alvorlige traumer. CT gir også en akseptabel fremstilling av bløtdeler og skiveprolapser i lumbalryggen og vil være et alternativ til MR i utredning av isjias. Strålebelastningen ved CT columna er ikke ubetydelig, og den kan være høyere ved volumopptak enn ved konvensjonelle transversale snitt. Dette må tas med i betraktningen når det gjelder valg av bildemetode.

Konvensjonell røntgen gir god oversikt over akseforholdene i columna samt over degenerative forandringer $i$ form av påleiringer og høydereduserte skiver. Destruksjoner av tumor eller infeksjon kan fremstilles, men med lavere sensitivitet enn med MR. Frakturer kan fremstilles, men med lavere sensitivitet enn ved CT. Konvensjonell røntgenundersøkelse er derfor ikke førstevalget i utredningen av ryggsmerter (9), men kan være indisert ved mistanke om osteoporotiske frakturer og ved lettere traumer $(1,3)$.

Myelografi, eventuelt kombinert med CT, har $\mathrm{i}$ dag liten anvendelse, men når $\mathrm{MR}$ er kontraindisert kan dette være en nøyaktig og god metode for å fremstille plassforholdene for medulla og nerverøtter (1).

\section{Vanlige bildefunn ved nakke- og ryggsmerter \\ Degenerative skiver}

Tradisjonelt har man knyttet degenerative forandringer i rygg og nakke til mekanisk belastning - for eksempel er degenerasjon mest uttalt cervikalt i nivåene C5/C6 og C6/ C7 og lumbalt i de to nederste nivåene, der belastningen er størst. Et begrep som «slitasjeforandringer» støtter opp om oppfatningen at den mekaniske belastningen er viktig. Imidlertid har tvillingstudier vist at så mye som $50-70 \%$ av forskjellene i graden av degenerasjon ulike individer imellom kan tilskrives genetiske faktorer (10).

Mellomvirvelskivene består av en indre nucleus pulposus, som er en geléliknende støtpute av vann og proteoglykaner, samt en ytre anulus fibrosus, som består av tettpakkede fibre. Med alderen reduseres mengden vann i nucleus pulposus, og gradvis blir skiven mer fibrøs og uten noe klart skille mel- lom nucleus og annulus (11). Disse endringene kan fremstilles på MR. Hos barn og unge har en normal mellomvirvelskive høyt signal på T2-vektede bilder som tegn på høyt væskeinnhold, men allerede ved 30 års alder blir skiven normalt gradvis mørkere på grunn av at innholdet av væske har minsket (fig 1). Signalintensiteten i skivene er klart korrelert til alder, $90 \%$ av asymptomatiske 60 -åringer vil ha slike signalforandringer $\mathrm{i}$ skivene $(11,12)$. Det er ikke vist noen sikker og klinisk viktig sammenheng mellom forekomsten av slike degenerative skiveforandringer og pasientens symptomer verken $\mathrm{i}$ nakke eller i rygg $(13,14)$. Disse skiveforandringene må altså oppfattes som del av den normale aldringen.

Annulusrupturer er konsentriske eller radiære sprekker i anulus fibrosus. De ses på T2-vektede MR-bilder som områder med høyt signal i kanten av skiven (high intensity zone, HIZ), typisk i midtlinjen inn mot spinalkanalen i de nederste lumbale skivene (fig 2). Det har vært hevdet at annulusruptur kan gi ryggsmerter gjennom enten direkte mekanisk påvirkning av smerteførende fibre i kanten av skiven eller ved lekkasje av inflammatorisk aktive substanser fra nucleus pulposus (13). Imidlertid er dette et hyppig funn også hos asymptomatiske personer. I en normalpopulasjon av 40-åringer i Danmark (15) hadde ca. $40 \%$ annulusruptur, og det var bare en moderat assosiasjon med kroniske ryggsmerter. Funn av slike rupturer på MR-bilder må ses som en del av utviklingen av skivedegenerasjon, men funnet i seg selv kan ikke tillegges noen vesentlig betydning som årsak til symptomer.

\section{Skiveprolaps}

Hos pasienter med smerter lavt i ryggen med utstråling er det rapportert en prevalens av lumbale skiveprolapser på $65 \%$, mens prevalensen ved smerter uten utstråling var $57 \%$ (16). Imidlertid finner man også lumbale prolapser hos $25 \%$ i en normalpopulasjon (15). Også i cervikalcolumna har skivebukinger og prolapser en høy prevalens hos asymptomatiske, den er over $50 \%$ i aldersgruppen over 64 år (17). Det å ha skiveprolaps er altså ikke ensbetydende med å ha symptomer.

Prolapser som disloserer eller komprimerer nerverøtter er imidlertid sjeldent hos symptomfrie $(15,18)$ (fig 3$)$. Finner man denne typen prolaps kombinert med symptomer som passer med den aktuelle nerverot, vil man ha etablert en sannsynlig årsakssammenheng. Prolapser er ikke stabile strukturer. Særlig de som har en smal basis mot skiven viser stor tendens til resorpsjon. Under konservativ behandling vil en tredel skrumpe i løpet av de første seks uker og to tredeler i løpet av seks måneder (13). Funn av skiveprolaps er altså i seg selv ikke indikasjon for kirurgisk behandling. Som alltid er det kliniske bildet avgjørende.

Etter prolapskirurgi blir de fleste raskt

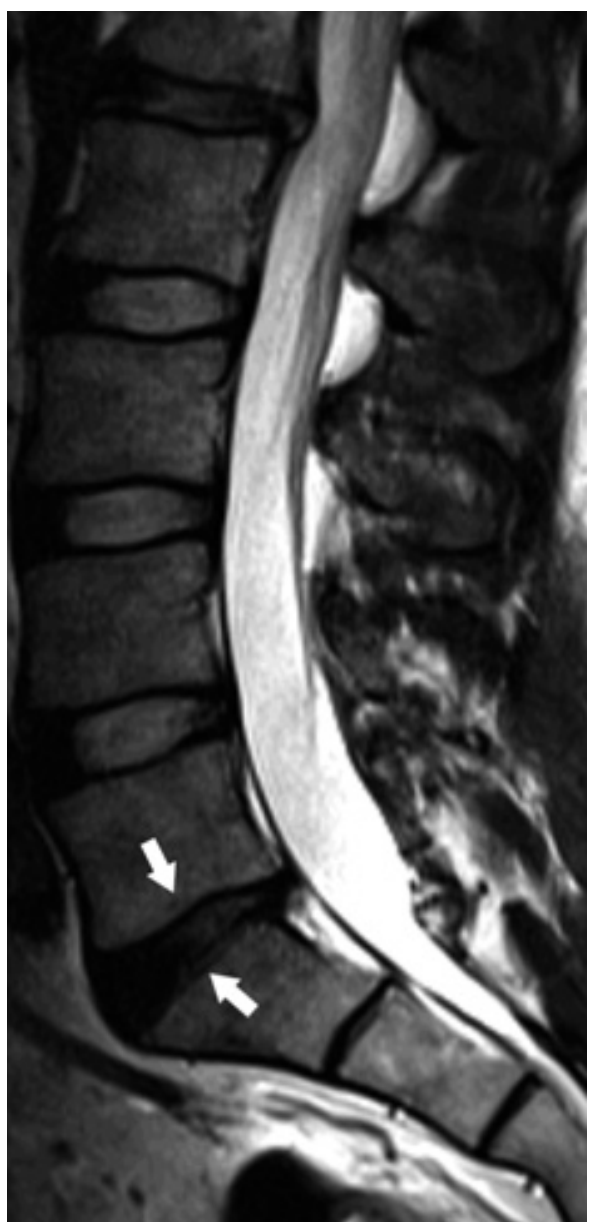

Figur 1 Sagittalt T2-vektet bilde av lumbosakralcolumna som viser lett grad av skivedegenerasjon med mørk skive (piler) i nivå L5/S1

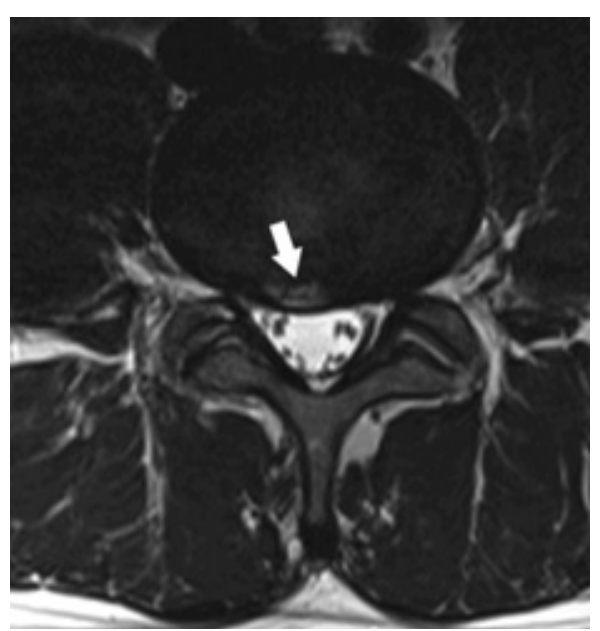

Figur 2 Transversalt T2-vektet bilde av skivebuking og annulusruptur (pil) i L4/L5-nivå

symptomfrie, men utilfredsstillende resultat fører til reoperasjon hos 5-18\% (19). Én årsak til at pasienten ikke blir kvitt sine plager, er at prolapsmaterialet ikke er fjernet tilstrekkelig, altså restprolaps. En annen årsak er at nytt skivemateriale kommer ut gjennom defekten i anulus fibrosus. Dette kalles residivprolaps. Ved kirurgisk fjerning av skiveprolaps i lumbalryggen fjernes en del av lamina for å få tilgang til spinalkanalen. 


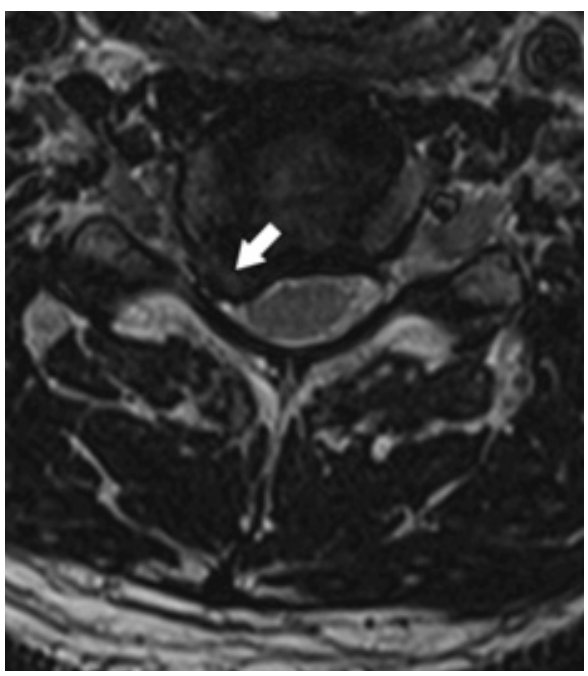

Figur 3 Transversalt T2-vektet bilde av cervikalt prolaps (pil) som gir innsnevring av høyre sides rotkanal

Operasjonen fører ofte til arrdanning i epiduralrommet på operasjonsnivået. På CT og på MR uten kontrastvæske kan det være vanskelig å skille arrvev fra prolaps. Derfor kan det være indisert å gi intravenøs MRkontrastvæske. Arrvev vil ofte lade opp kontrast, mens skivematerialet som regel er avaskulært og dermed ikke tar opp kontrast (20). Ved kirurgisk behandling av cervikale prolapser er tilgangen som regel fra ventralsiden av cervikalcolumna uten at man åpner inn til spinalkanalen, arrdanning i epiduralrommet er derfor et mindre problem (20). Ved MR-undersøkelser for problemstillingen restprolaps eller residivprolaps i cervikalcolumna er kontrastvæske derfor som regel ikke nødvendig.

En spesiell type prolaps ses når skivemateriale presses gjennom dekkplatene på virvelcorpus. Dette kalles intravertebrale prolapser eller Schmorls knuter. Slike er et vanlig funn $\mathrm{i}$ en normalbefolkning (13) og oppfattes å være uten klinisk betydning.

Degenerative forandringer i beinmargen Inn mot degenerative mellomvirvelskiver kan man på MR se signalforandringer i dekkplatene og i beinmargen i tilstøtende virvelcorpora. Dette kalles Modic-forand-
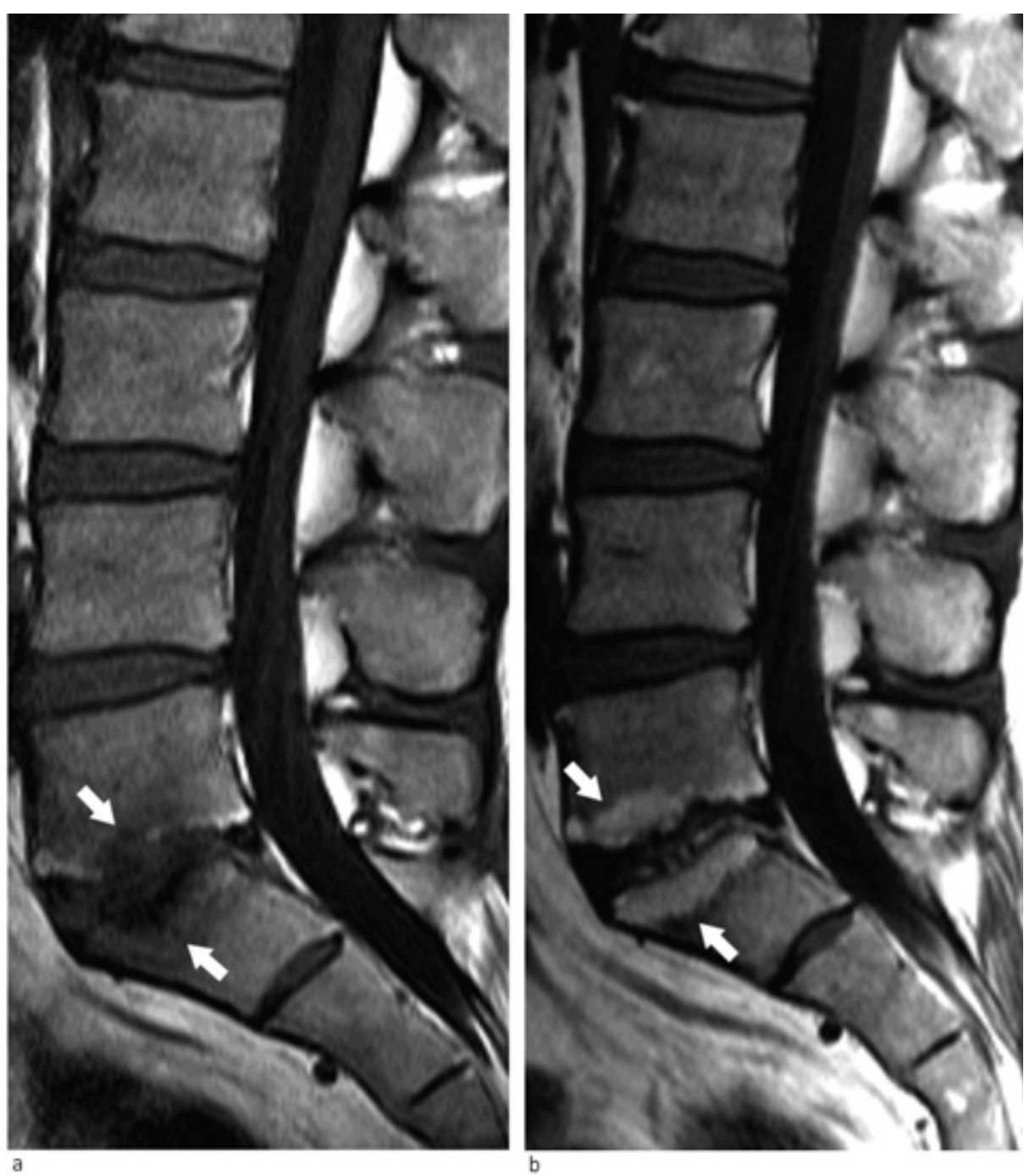

Figur 4 Sagittale T1-vektede bilder av degenerative beinmargsforandringer (Modic-forandringer). a) Type 1 med lavt T1-signal som tegn på ødem inn mot skiven L5/S1 (piler). b) Samme pasient ett år senere - omdanning til type 2 med høyt signal (piler) som uttrykk for fett

ringer og er vanligst i nivåene L4/L5 og L5/ S1 (21). Det er to hovedtyper av disse beinmargsforandringene. Type 1 har lavt signal på T1-vektede bilder og høyt signal på T2vektede som uttrykk for en inflammatorisk reaksjon med beinmargsødem. Type 2 har høyt T1-signal og høyt T2-signal som tegn på fettomdanning av den røde beinmargen.

I en systematisk litteraturoversikt var median prevalens av Modic-forandringer $43 \%$ hos pasienter med smerter lavt i ryggen og/ eller isjias, men bare $6 \%$ i normalpopulasjonen (22). En dansk populasjonsstudie av 40åringer viste at det var sammenheng mellom Modic-forandringer og forekomst av uspesifikke smerter lavt i ryggen (15). Slike beinmargsforandringer er ikke stabile. Over tid kan type 1 overgå til type 2 , men de kan også forsvinne av seg selv (23) (fig 4). Den kliniske betydningen av Modic-forandringer er fortsatt usikker. Eventuelle terapeutiske konsekvenser undersøkes i pågående studier.

\section{Fasettleddsartrose og dekkplatepåleiringer} Intervertebralleddet har tre komponenter leddet mellom endeplate-mellomvirvelskive-endeplate og de to fasettleddene. Disse leddene stabiliserer hverandre. Utvikler det seg degenerasjon i mellomvirvelskiven, øker belastningen på og dermed sannsynligheten for degenerasjon også i fasettleddene. Funnene ved fasettleddsdegenerasjon er tilsvarende det man ser i andre synovialledd, det vil si reduksjon i brusktykkelse, subkondral sklerose, subkondrale cyster og osteofyttdanning. Osteofyttene kan rage inn i rotkanalene eller i de laterale recesser i spinalkanalen og gi opphav til rotkompresjon eller spinal stenose. Sekundært til fasettleddsartrosen kan man se hypertrofi av ligamentum flavum, som bidrar til å innsnevre plassforholdene. Degenerative fasettledd er en hyppig årsak til olistese, der en virvelcorpus glir i ventral retning i forhold til den underliggende virvelcorpus, vanligst i L4/L5nivå. En slik degenerativ glidning, ofte kalt pseudospondylolistese, kan gi reduserte plassforhold både i spinalkanalen og i rotkanalene.

I cervicalcolumna er rotkanalen begrenset av fasettleddet dorsalt og uncovertebralleddet ventralt. Uncovertebralleddet er lokalisert mellom virvelens dekkplate og kanten på mellomvirvelskivens fiberbrusk på hver side. Osteofytter på disse leddene vil rage inn mot rotkanalene og er en vanlig årsak til nerverotskompresjon, særlig i nivåene C5/C6 og C6/C7 (14). Som en del av den degenerative prosessen i mellomvirvelskivene ses ofte nebbformede osteofytter på dekkplatene til virvelcorpus. Sannsynligvis skjer dette som et forsøk på å stabilisere segmentet ved å øke den vektbærende overflaten på endeplatene (21). Vanligvis er disse osteofyttene lokalisert ventralt og uten klinisk betydning, men hvis de rager fra dorsalsiden inn mot spinalkanalen, vil de kunne komprimere medulla eller nerverøtter. Sær- 
lig i de nederste cervikale nivåene er dette en viktig årsak til kompresjon av medulla og kan gi symptomer på myelopati (24).

\section{Spinal stenose}

Reduserte plassforhold i spinalkanalen er ofte et resultat av degenerasjon. Prevalensen av spinal stenose øker med stigende alder. Det er typisk en kombinasjon av skivebuking, fasettleddspåleiringer og hypertrofisk ligamentum flavum som forårsaker stenosen. Det er ingen nøyaktig sammenheng mellom graden av stenose og pasientens symptomer, og det er ingen allment akseptert grense for hvor trang spinalkanalen må være før man kan bruke begrepet «spinal stenose» $(2,13)$. Dette er ikke en statisk tilstand. Typisk er det at plassforholdene blir bedre ved kyfosering og reduseres ved lordosering. Når pasienten undersøkes i ryggleie med flekterte knær, vil man ofte få inntrykk av mer rommelige forhold enn hvis vedkommende undersøkes stående. Dette har vært anført som et argument for å undersøke slike pasienter med vertikale MRmaskiner hvor pasienten kan stå under bildeopptaket, men som regel er forskjellene så små at man ikke vil gi en generell anbefaling om stående MR-undersøkelse hos denne pasientgruppen.

\section{Konklusjon}

Utviklingen innenfor bildediagnostikken har ført til at man nå i detalj kan kartlegge de morfologiske forhold i rygg og nakke. Ulike degenerative forandringer som blir påvist gir mange ganger ikke noe bidrag når det gjelder valg av behandling. Det er også ofte vanskelig å fastslå i hvilken grad morfologiske forandringer i rygg og nakke forklarer pasientens symptomer. Hvorfor samme bildefunn ser ut til å ligge bak invalidiserende symptomer hos noen, men ikke gir plager hos andre, vet man fortsatt lite om. Det er derfor avgjørende at bildefunnene isolert ikke danner grunnlag for behandling, de må alltid vurderes i sammenheng med sykehistorie og kliniske funn. Det er også viktig at utredningen er godt begrunnet. Bildediagnostikk ved smerter i nakke eller rygg tilrår vi kun ved mulig alvorlig tilstand (røde flagg) eller der pasienten har vedvarende og uttalte symptomer etter 4-6 uker.

\section{Litteratur}

1. Formidlingsenheten for muskel- og skjelettlidelser og Sosial- og helsedirektoratet. Nasjonale kliniske retningslinjer. Korsryggsmerter med og uten nerverotaffeksjon. www.formi.no/index.php/ Helsepersonell/id/kliniske_retningslinjer/ (25.2.2010).

2. Ahmed M, Modic MT. Neck and low back pain: neuroimaging. Neurol Clin 2007; 25: 439-71.

3. Chou R, Qaseem A, Snow V et al. Diagnosis and treatment of low back pain: a joint clinical practice guideline from the American College of Physicians and the American Pain Society. Ann Intern Med 2007; 147: 478-91

4. Chou R, Fu R, Carrino JA et al. Imaging strategies for low-back pain: systematic review and metaanalysis. Lancet 2009: 373: 463-72.

5. Bussieres AE, Taylor JA, Peterson C. Diagnostic imaging practice guidelines for musculoskeletal complaints in adults - an evidence-based approach. Part 3: spinal disorders. J Manipulative Physiol Ther 2008; 31: 33-88.

6. Binder Al. Cervical spondylosis and neck pain BMJ 2007; 334: 527-31.

7. Lærum E, Brox JI, Werner EL. Vond rygg - fortsatt en klinisk utfordring. Tidsskr Nor Legeforen 2010. 130: $2248-51$

8. Nygaard $\emptyset \mathrm{P}, \mathrm{R} \emptyset \mathrm{M}$, Andersen $\mathrm{Tl}$ et al. Nakkesmerter med og uten nerverotsaffeksjon. Tidsskr Nor Legeforen 2010; 130: 2252-5.

9. Freund M, Sartor K. Degenerative spine disorders in the context of clinical findings. Eur J Radiol 2006; $58: 15-26$

10. Adams MA, Roughly PJ. What is intervertebral disc degeneration and what causes it? Spine 2006; 31 . $2151-61$

11. Malfair D, Baell DP. Imaging the degenerative diseases of the lumbar spine. Magn Reson Imaging Clin N Am 2007: 15: 221-38.

12. Shedid D, Benzel EC. Cervical spondylosis ana- tomy: pathophysiology and biomechanics. Neurosurgery 2007; 60 (suppl 1): 7-13.

13. Modic MT, Ross JS. Lumbar degenerative disk disease. Radiology 2007; 245: 43-61.

14. Abbed KM, Coumans JV. Cervical radiculopathy: pathophysiology, presentation, and clinical evaluation. Neurosurgery 2007; 60 (suppl 1): 28-34

15. Kjaer P, Lebouf-Yde C, Korsholm L et al. Magnetic resonance imaging and low back pain in adults: A diagnostic imaging study of 40 -year old men and women. Spine 2005; 30: 1173-80.

16. Modic MT, Obucowski NA, Ross JS et al. Acute low back pain and radiculopathy: MR imaging findings and their prognostic role and effect on outcome. Radiology 2005; 237: 597-604.

17. Teresi LM, Lufkin RB, Reicher MA et al. Asymptomatic degenerative disk disease and spondylosis of the cervical spine. Radiology 1987; 164: 82-8.

18. Weishaupt D, Zanetti M, Hodler J et al. MR imaging of the lumbar spine: prevalence of intervertebral disc extrusion and sequestration, nerve root compression, end plate abnormalities, and osteoarthritis of the facet joints in asymptomatic volunteers. Radiology 1988; 209: 661-6.

19. Vik A, Zwart JA, Hulleberg $G$ et al. Eight year outcome after surgery for lumbar disc herniation. Acta Neurochir 2001; 143: 607-11.

20. Ross JS. Magnetic resonance imaging of the postoperative spine. Semin Musculoskelet Radiol 2000 4: $281-91$.

21. Modic MT, Steinberg PM, Ross JS et al. Degenerative disk disease: assessment of changes in vertebral bone marrow with MR imaging. Radiology 1988; 166: 193-9

22. Jensen TS, Karppinen J, Sorensen JS et al. Vertebral endplate signal changes (Modic change): a systematic literature review of prevalence and association with non-specific low back pain. Eur Spine J 2008; 17: 1407-22

23. Rahme R, Moussa R. The Modic vertebral endplate and marrow changes: pathologic significance and relation to low back pain and segmental instability of the lumbar spine. AJNR Am J Neuroradiol 2008; 29: $838-42$

24. Baron EM, Young WF. Cervical spondylotic myelopathy: a brief review of its pathophysiology, clinical course and diagnosis. Neurosurgery 2007; 60 (suppl 1): 35-42.

Manuskriptet ble mottatt 31.8. 2009 og godkjent 25.2. 2010. Medisinsk redaktør Are Brean. 